\section{Supplemental Far-red Light-emitting Diode Light Increases Growth of Foxglove Seedlings Under Sole-source Lighting}

\author{
Claudia Elkins and Marc W. van Iersel
}

ADDITIONAL INDEX wORDs. Digitalis purpurea, LED, ornamental seedlings, phytochrome, shade

Summary. Seedlings may be grown indoors where environmental conditions can be precisely controlled to ensure consistent and reliable production. The optimal spectrum for production under sole-source lighting is currently unknown. Far-red light $(\lambda=700-800 \mathrm{~nm})$ typically is not a significant part of the spectrum of lightemitting diode (LED) grow lights. However, far-red light is photosynthetically active and can enhance leaf elongation, which may result in larger leaves and increased light interception. We hypothesized that adding far-red light to sole-source lighting would increase the growth of 'Dalmatian Peach' foxglove (Digitalis purpurea) seedlings grown under white LED lights, potentially shortening production times. Our objective was to evaluate the effect of far-red light intensities, ranging from 4.0 to $68.8 \mu \mathrm{mol} \cdot \mathrm{m}^{-2} \cdot \mathrm{s}^{-1}$, on the growth and morphology of foxglove seedlings. Foxglove seedlings were grown in a growth chamber with a photosynthetic photon flux density $(P P F D)$ of $186 \pm 6.4 \mu \mathrm{mol} \cdot \mathrm{m}^{-2} \cdot \mathrm{s}^{-1}$ and supplemental far-red light intensities ranging from 4.0 to $68.8 \mu \mathrm{mol} \cdot \mathrm{m}^{-2} \cdot \mathrm{s}^{-1}$. As far-red light increased, shoot dry weight, root dry weight, plant height, and plant height/ number of leaves increased by $38 \%(P=0.004), 20 \%(P=0.029), 38 \%(P=0.025)$, and $34 \%(P=0.024)$, respectively, while root weight fraction decreased $16 \%(P=$ 0.034). Although we expected supplemental far-red light to induce leaf and/or stem expansion, specific leaf area and compactness (two measures of morphology) were unaffected. Because a $37 \%$ increase in total photon flux density ( $P P F D$ plus farred light) resulted in a $34.5 \%$ increase in total plant dry weight, the increased growth likely was due to increased photosynthesis rather than a shade-acclimation response. The growth response was linear across the 4.0 to $68.8 \mu \mathrm{mol} \cdot \mathrm{m}^{-2} \cdot \mathrm{s}^{-1}$ range of farfed light tested, so we were unable to determine a saturating far-red photon flux density.

$\mathrm{P}$ oduction of young plants, such as seedlings and cuttings, under sole-source lighting is an alternative to greenhouse production where the natural daily light integral (DLI) in winter may be too low for the production of high-quality young plants (Randall and Lopez, 2015). Because the electrical cost associated with lighting are high, it is important that young plants use the provided light as efficiently as possible. Young seedlings intercept little of the light

Received for publication 28 May 2020. Accepted for publication 16 July 2020.

Published online 18 August 2020.

Department of Horticulture, University of Georgia, 1111 Miller Plant Science Building, Athens, GA 30602

This work was funded by USDA-NIFA-SCRI Award No. 2018-51181-28365, Project "Lighting Approaches to Maximize Profits," and the American Floral Endowment.

M.W.V.I. is the corresponding author. E-mail: mvanier@ uga.edu.

This is an open access article distributed under the CC BY-NC-ND license (https://creativecommons.org/ licenses/by-nc-nd/4.0/).

https://doi.org/10.21273/HORTTECH04661-20 available to them in a production space because their leaves are small relative to the size of the production space. For example, 'Goldsturm' black-eyed susan (Rudbeckia fulgida var. sullivantii) seedlings sown in a 72 -cell plug tray $(20 \times 10$ inches $)$ had a total canopy size of $\approx 15 \mathrm{~cm}^{2}$ after $10 \mathrm{~d}$, which represented $\approx 1 \%$ of the surface area of the tray (Elkins, from larger leaves to increase light interception and presumably canopy photosynthesis and growth. This has 2020). Plants this small may benefit the potential to shorten cropping cycles of ornamental plants grown in controlled environments. One approach to enhancing growth is to include far-red light $(\lambda=700-800$ $\mathrm{nm}$ ) in the spectrum because 1) farred light can trigger a shade-avoidance and/or acclimation response (Franklin, 2008; Keuskamp et al., 2010; Possart et al., 2014) and 2) it is photosynthetically active (Zhen and Bugbee, 2020; Zhen and van Iersel, 2017).

Shade-avoidance/acclimation responses are mediated by phytochrome, a pigment-protein photoreceptor that detects light intensity and quality. Phytochrome has two photointerconvertible forms, the inactive red $(\mathrm{Pr})$ and the active far-red (Pfr) forms. These allow plants to detect the red to far-red (R:FR) ratio of incident light that mediates a response in plants (Franklin and Whitelam, 2005; Possart et al., 2014; Ruberti et al., 2012). Red light is strongly absorbed, whereas far-red light is poorly absorbed and thus transmitted through leaves. Under-canopy plants are thus exposed to a low R:FR ratio, triggering shade responses (Casal, 2013; Franklin and Whitelam, 2005; Gommers et al., 2013). In response to shade, plants may respond morphologically, such as via elongated stems and petioles (shade-avoidance) (Franklin, 2008; Franklin and Whitelam, 2005) or may acclimate with traits such as increased specific leaf area (SLA) (shade-tolerance) (Evans and Poorter, 2001; Gommers et al., 2013; Gong et al., 2015). Excessive elongation is undesirable in seedling production and a potential drawback to providing high levels of far-red light. Compared with the PPFD, sunlight has about $19 \%$ far-red photons [701-750 nm, the range most responsible for phytochrome responses

\begin{tabular}{llll}
\hline $\begin{array}{l}\text { Units } \\
\text { To convert U.S. to SI, } \\
\text { multiply by }\end{array}$ & U.S. unit & SI unit & $\begin{array}{l}\text { To convert SI to U.S., } \\
\text { multiply by }\end{array}$ \\
\hline $\mathrm{l}$ & $\mathrm{cbar}$ & $\mathrm{kPa}$ & $\mathrm{l}$ \\
0.3048 & $\mathrm{ft}$ & $\mathrm{m}$ & 3.2808 \\
0.0283 & $\mathrm{ft}^{3}$ & $\mathrm{~m}^{3}$ & 35.3147 \\
2.54 & inch $(\mathrm{es})^{\mathrm{inch}}$ & $\mathrm{cm}$ & 0.3937 \\
6.4516 & $\mathrm{inc}^{2}$ & $\mathrm{~cm}^{2}$ & 0.1550 \\
0.2276 & inch $^{2} / \mathrm{oz}$ & $\mathrm{cm}^{2} \cdot \mathrm{g}^{-1}$ & 4.3942 \\
28.3495 & $\mathrm{oz}$ & $\mathrm{g}$ & 0.0353 \\
93.0102 & $\mathrm{oz} / \mathrm{ft}$ & $\mathrm{g} \cdot \mathrm{m}^{-1}$ & 0.0108 \\
1 & $\mathrm{ppm}$ & $\mathrm{mg} \cdot \mathrm{L}^{-1}$ & 1 \\
$\left({ }^{\circ} \mathrm{F}-32\right) \div 1.8$ & ${ }^{\circ} \mathrm{F}$ & ${ }^{\circ} \mathrm{C}$ & $\left({ }^{\circ} \mathrm{C} \times 1.8\right)+32$
\end{tabular}


(Zhen and Bugbee, 2020)], so plants are accustomed to receiving a substantial amount of far-red light.

For decades, far-red light has been considered outside of the range of photosynthetically active radiation [PAR (400-700 nm)], as established by Hoover (1937), McCree (1971), and Inada (1976), even though they demonstrated that far-red light had at least some photosynthetic activity. Recently, Zhen and van Iersel (2017) found a synergistic interaction between far-red light and $P A R$, specifically an increase in net photosynthesis of lettuce (Lactuca sativa) in response to added far-red light. Zhen and Bugbee (2020) found that adding far-red light (up to $40 \%$ of $P A R$ ) increased canopy photosynthesis of 14 diverse agronomic and horticultural crop species as much as adding the same photon flux of $P A R$.

Previous studies examining the effect of far-red light on plant growth (Hurt et al., 2019; Li and Kubota, 2009; Meng and Runkle, 2019; Meng et al., 2019; Park and Runkle, 2016, 2017; Zou et al., 2019) and photosynthesis (Zhen and Bugbee, 2020; Zhen and van Iersel, 2017) have evaluated several intensities of far-red light, ranging from 0 to 160 $\mu \mathrm{mol} \cdot \mathrm{m}^{-2} \cdot \mathrm{s}^{-1}$. Saturation levels have been determined for leaf and wholeplant photosynthesis (Zhen and Bugbee, 2020; Zhen and van Iersel, 2017), but not for growth responses. Our objective was to evaluate 18 intensities of supplemental far-red light, ranging from 4.0 to $68.8 \mu \mathrm{mol} \cdot \mathrm{m}^{-2} \cdot \mathrm{s}^{-1}$, on the growth and morphology of 'Dalmatian Peach' foxglove (Digitalis purpurea) seedlings. Foxglove was selected because it is a popular garden plant and one of the few perennials propagated from seed. It can grow well under a wide range of light conditions, and thus it appears to have the ability to acclimate to a range of light environments. We hypothesized that providing supplemental far-red light would result in leaf expansion, increased photosynthesis, and therefore more growth, but that above a certain photon flux, plant morphology and growth would no longer respond to further increases in far-red light.

\section{Materials and methods}

CONTROLLED ENVIRONMENT SET UP AND TREATMENTS. A $54-\mathrm{m}^{3}$ walk-in growth chamber was used for this study. It contained three metal shelving racks with three, $8 \times 2$ - $\mathrm{ft}$ shelves per rack. Ebb and flow trays were placed on each shelf and connected to a subirrigation system. Aluminum foil-covered polystyrene was used to divide each shelf into two equal $4 \times 2$ $\mathrm{ft}$ growing sections for a total of 18 sections. The ends of each growing section were closed off with polystyrene, and an opaque black curtain was hung between the racks to prevent light pollution between neighboring sections. In each section, two white light-emitting diode (LED) light bars (SPYDRx Plus with PhysioSpec indoor spectrum; Fluence Bioengineering, Austin, TX) were installed 37.5 $\mathrm{cm}$ above the tray bottom. The PPFD in each section was measured with a spectroradiometer (SS-110; Apogee Instruments, Logan, UT) and averaged $( \pm \mathrm{SD}) 186 \pm 6.4 \mu \mathrm{mol} \cdot \mathrm{m}^{-2} \cdot \mathrm{s}^{-1}$ plus 4.0 to $4.7 \mu \mathrm{mol} \cdot \mathrm{m}^{-2} \cdot \mathrm{s}^{-1}$ of far-red light $(700-800 \mathrm{~nm})$. Five of the six sections in each rack were equipped with a custom-made dimmable far-red LED light bar (Fluence Bioengineering) installed $37.5 \mathrm{~cm}$ above the tray bottom to provide additional far-red light. The 15 far-red LED light bars (peak at 734 $\mathrm{nm}$, full width at half maximum $21 \mathrm{~nm}$ ) were connected to five separate dimmable drivers (PLDI00-ITCFI4A-2100; FSP Powerland Technology, Nanjing, China). Three far-red light bars, one from each rack, were connected to each dimmable driver. Dimming inputs of the drivers were connected to a fourchannel analog output module (SDMAO4A; Campbell Scientific, Logan, UT) that was connected to a datalogger (CR6, Campbell Scientific), which allowed us to control the amount of additional far-red light by providing $0 \mathrm{mV}$ (light off) to $10,000 \mathrm{mV}$ (light on full power) dimming signals to the drivers.

Because all the far-red light bars provided different amounts of far-red light at full power, we were not able to achieve five distinct levels of far-red light. Instead, we aimed to get a wide range of far-red light intensities, with those intensities as evenly distributed as possible. This resulted in far-red light intensities ranging from of 7.9 to $68.8 \mu \mathrm{mol} \cdot \mathrm{m}^{-2} \cdot \mathrm{s}^{-1}$ among the 15 sections with a far-red light bar. Figure 1 shows the spectral distribution of the white LED light bars with added low or high amounts of far-

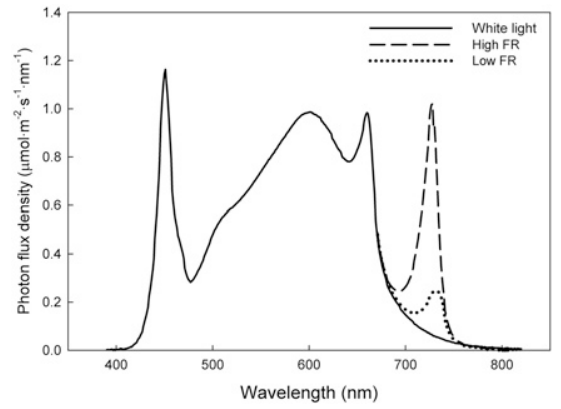

Fig. 1. Spectral distribution of white light-emitting diode (LED) bars with added low or high amounts of far-red (FR) light.

red light. To measure the light spectrum, 18 readings, evenly spaced to cover the $1.0 \times 0.25-\mathrm{m}$ area directly below the light bars, were taken in each of the 18 sections using a spectroradiometer (SS-110) and SpectroVision software (version 1.02.005, Apogee Instruments) with the integration range set to 700 to $800 \mathrm{~nm}$ to quantify the total amount of far-red light in the spectrum. Table 1 shows the total far-red light $(700-800 \mathrm{~nm})$ in each treatment and corresponding values of phytochrome photoequilibrium (PPE) and R:FR ratio (R, 635$685 \mathrm{~nm}$; FR, 710-760 nm), as reported by SpectroVision. The default wavebands used by SpectroVision to calculate R:FR coincide with those with the greatest effect on PPE. Table 1 also includes the calculated PPFD to far-red ratio (PPFD, 400-700 nm; FR, 700-800 nm) and percent far-red calculated as: far-red $(700-800 \mathrm{~nm}) /[P P F D(400-700 \mathrm{~nm})+$ far-red $(700-800 \mathrm{~nm})] \times 100$.

Air temperature was controlled with a thermostat (PENN A19BAC; Johnson Controls, Milwaukee, WI), and humidity was controlled with a dehumidifier (FAD704DWD13; Electrolux, Charlotte, NC). Temperature, humidity, and carbon dioxide $\left(\mathrm{CO}_{2}\right)$ sensors were connected to a datalogger (CR6) to measure and record environmental conditions in the chamber. Air temperature and relative humidity were measured with a combined probe (HMP50; Vaisala, Helsinki, Finland). Carbon dioxide concentration was measured with $\mathrm{a} \mathrm{CO}_{2}$ transmitter (GMC20; Vaisala), and the datalogger maintained the desired $\mathrm{CO}_{2}$ concentration by triggering a solenoid valve to open and release $\mathrm{CO}_{2}$ from a compressed gas cylinder for 1 -s intervals whenever the 
Table 1. Phytochrome photoequilibrium (PPE), red to far-red (R:FR) ratio, photosynthetic photon flux density (PPFD) to FR (PPFD:FR) ratio, and percent FR corresponding to the total amount of FR light provided in each treatment. The two white light-emitting diode (LED) light bars in each section provided some FR light. The top three rows represent lighting treatments without added FR light.

\begin{tabular}{ccccc}
\hline FR $\left(\boldsymbol{\mu m o l} \cdot \mathbf{m}^{-2} \cdot \mathbf{s}^{-1}\right)^{\mathrm{z}}$ & PPE $^{\mathrm{y}}$ & R:FR $(\text { ratio })^{\mathrm{x}}$ & ${\text { PPFD:FR }(\text { ratio })^{\mathrm{w}}}$ & ${\text { FR }(\%)^{\mathbf{v}}}^{-}$ \\
\hline 4.0 & 0.86 & 13.7 & 45.1 & 2.2 \\
4.4 & 0.86 & 13.7 & 43.9 & 2.2 \\
4.7 & 0.86 & 12.1 & 37.8 & 2.6 \\
7.9 & 0.85 & 6.2 & 23.8 & 4.0 \\
9.2 & 0.84 & 5.1 & 20.1 & 4.7 \\
10.5 & 0.84 & 4.3 & 16.8 & 5.6 \\
11.1 & 0.83 & 4.0 & 16.3 & 5.8 \\
12.5 & 0.83 & 3.5 & 14.3 & 6.5 \\
12.8 & 0.83 & 3.7 & 14.9 & 6.3 \\
13.4 & 0.83 & 3.5 & 13.9 & 6.7 \\
24.7 & 0.79 & 1.8 & 7.4 & 11.9 \\
37.4 & 0.75 & 1.1 & 4.8 & 17.3 \\
48.5 & 0.73 & 0.9 & 3.9 & 20.5 \\
49.5 & 0.73 & 0.9 & 3.8 & 20.7 \\
63.3 & 0.70 & 0.7 & 3.2 & 24.0 \\
63.6 & 0.70 & 0.7 & 3.0 & 25.0 \\
64.4 & 0.70 & 0.7 & 3.1 & 24.7 \\
68.8 & 0.68 & 0.6 & 2.7 & 26.9 \\
\hline
\end{tabular}

${ }^{\mathrm{z}}$ Amount of FR light: photon flux integral between 700 and $800 \mathrm{~nm}$.

y Sager et al. (1988).

${ }^{\mathrm{x}}$ Ratio of photon flux integral of red $(635-685 \mathrm{~nm})$ to FR $(710-760 \mathrm{~nm})$.

"Ratio of PPFD (400-700 nm) to FR $(700-800 \mathrm{~nm})$.

${ }^{\mathrm{v}} \mathrm{FR}(700-800 \mathrm{~nm}) /[\operatorname{PPFD}(400-700 \mathrm{~nm})+\mathrm{FR}(700-800 \mathrm{~nm})] \times 100 \%$.

$\mathrm{CO}_{2}$ concentration dropped below $800 \mu \mathrm{mol} \cdot \mathrm{mol}^{-1}$.

Plant material and growing Conditions. On 25 Sept. 2018, 'Dalmatian Peach' foxglove seeds were sown in 72-cell trays filled with a soilless growing medium (Fafard 3B; Sun Gro Horticulture, Agawam, MA). One seedling tray was placed in each growing section. Seeds were germinated under white LED light only. Plants were subirrigated as needed, every 2 to $3 \mathrm{~d}$, with a $100 \mathrm{ppm}$ nitrogen water-soluble fertilizer solution $[15 \mathrm{~N}-2.2 \mathrm{P}-12.5 \mathrm{~K}$ (Peters Excel 15-5-15 Cal-Mag Special; ICL Fertilizers, Dublin, OH)]. On 16 Oct. 2018,21 d after seeds were sown, trays were thinned to one seedling per cell, and the far-red light treatments were initiated. Over the duration of the study, seedlings were grown at an air temperature of (mean $\pm \mathrm{SD}) 21.5 \pm$ $0.2^{\circ} \mathrm{C}$, a 16 -h photoperiod, PPFD of $186 \pm 6.4 \mu \mathrm{mol} \cdot \mathrm{m}^{-2} \cdot \mathrm{s}^{-1}$, DLI of $10.7 \pm$ $0.4 \mathrm{~mol} \cdot \mathrm{m}^{-2} \cdot \mathrm{d}^{-1}$, vapor pressure deficit of $1.3 \pm 0.1 \mathrm{kPa}$, and $\mathrm{CO}_{2}$ concentration of $800 \pm 15 \mu \mathrm{mol} \cdot \mathrm{mol}^{-1}$.

Plant measurements and STATISTICAL ANALYSIS. On 19 Nov. $2018,55 \mathrm{~d}$ after the seeds were sown, plants were harvested. Chlorophyll content index (CCM-200 plus; OptiSciences, Hudson, NH) measurements were taken on five mature leaves per treatment. The number of plants per 72-cell tray were counted. Five representative plants from each treatment tray were removed. Height (from media surface to tallest point) was measured, number of leaves were counted, and leaf area (LI-3100; LICOR Biosciences, Lincoln, NE) was measured on these five plants. Shoots were cut from the roots and dried in an oven at $80{ }^{\circ} \mathrm{C}$ for $\geq 5 \mathrm{~d}$ to obtain dry weight. Roots were washed, dried, and weighed as well. Shoots from the remaining viable plants ( $\geq$ four true leaves) in each tray were removed and dried to obtain dry weight. Mean shoot dry weight was calculated by adding the shoot dry weight of the five representative plants to the shoot dry weight of the remaining harvested plants, divided by the total number of plants harvested. For the five representative plants from each treatment, SLA was calculated by dividing total leaf area by total shoot dry weight, compactness was calculated by dividing shoot dry weight by plant height, leaf size was calculated as leaf area divided by the number of leaves, and root weight fraction was calculated by dividing root dry weight by total dry weight. SigmaPlot (version 11.0; Systat Software, San Jose, CA) was used to analyze the data using linear regression. We initially analyzed our data with PPE, R:FR, and far-red intensity as the explanatory variable, all giving similar results. Because we directly manipulated far-red light intensity, with changes in PPE and R:FR as secondary responses to those treatments, all data are presented as a function of far-red light intensity.

\section{Results and discussion}

Although initial germination percentage was good and there were seedlings in each cell, timing of germination was uneven, a common problem with foxglove (Purdue University, 1997). As a result, some seedlings that germinated later were shaded out by neighboring seedlings, resulting in nonviable transplants. The number of viable seedlings harvested per 72 -cell tray ranged from 41 to 72 with an average of 60 plants, and this was unaffected by treatment. Foxglove seedlings that received more farred light were larger; i.e., they had greater shoot and root dry weight and were taller. Shoot dry weight increased linearly from 0.32 to $0.44 \mathrm{~g} /$ plant $(38 \%)$ as far-red light increased from 4.0 to $68.8 \mu \mathrm{mol} \cdot \mathrm{m}^{-2} \cdot \mathrm{s}^{-1}$ (Fig. 2A). Previous studies reported similar increases in shoot dry weight in lettuce when far-red light was added to a constant PPFD (Li and Kubota, 2009; Meng and Runkle, 2019; Stutte et al., 2009). Park and Runkle (2017) also reported increased shoot dry weight in geranium (Pelargonium $\times$ hortorum), petunia (Petunia $\times$ bybrida), and snapdragon (Antirrbinum majus)-but not shade-tolerant impatiens (Impatiens walleriana)-in response to added far-red light, highlighting species-specific responses. We did not see a significant effect of far-red light on the number of leaves, which averaged 5.9 leaves per plant.

We observed a less-pronounced increase in root dry weight than in shoot dry weight. As far-red light increased from 4.0 to $68.8 \mu \mathrm{mol} \cdot \mathrm{m}^{-2} \cdot \mathrm{s}^{-1}$, root dry weight increased linearly from 0.083 to $0.100 \mathrm{~g} /$ plant [20\% (Fig. 2B)]. Meng and Runkle (2019) found a similar increase in root dry weight of 'Cherokee' red oakleaf lettuce (25\%) 
and basil [Ocimum basilicum ( $18 \%$ to $26 \%)]$ when $30 \mu \mathrm{mol} \cdot \mathrm{m}^{-2} \cdot \mathrm{s}^{-1}$ of far-red light was added to a mixture of blue and red light.

The size of the root system is the most important indicator of transplant readiness. Because far-red light increases root growth, it can shorten cropping cycles. In this study we saw a $20 \%$ increase in root dry weight over a 54-d growth period with the highest intensity of far-red light, which suggests

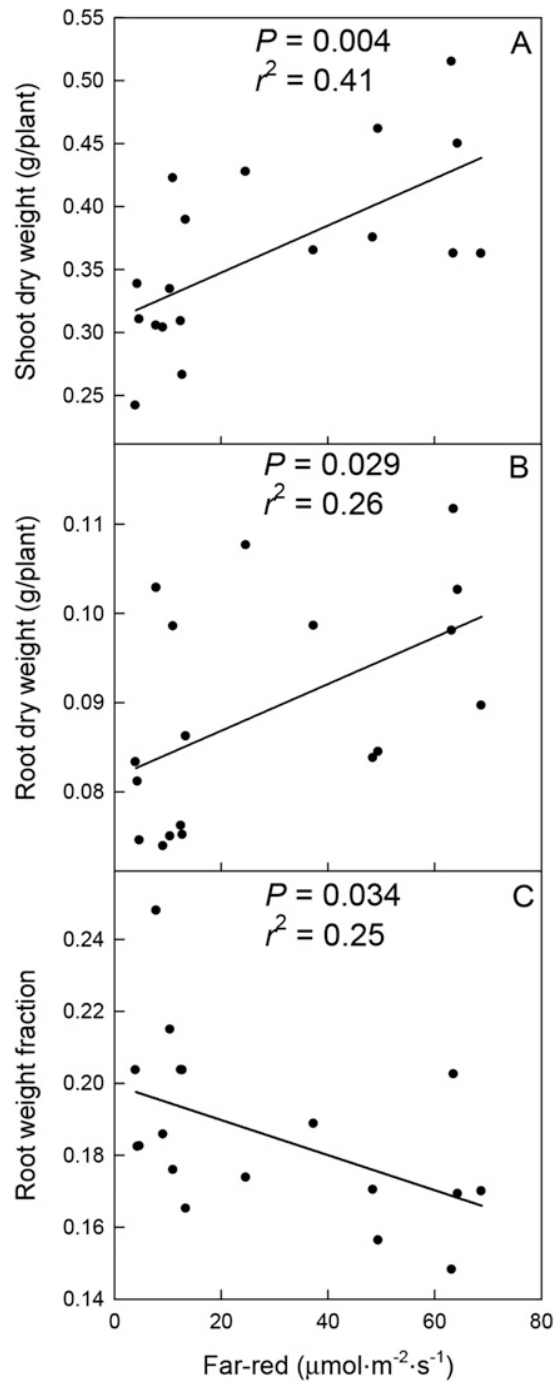

Fig. 2. (A) Shoot dry weight $(0.310+$ $0.00187 \times$ far-red $),(B)$ root dry weight $(0.082+0.0002618 \times$ far-red $)$, and (C) root weight fraction (root dry weight/total plant dry weight $=\mathbf{0 . 2 0 0}$ $0.0004878 \times$ far-red) of 'Dalmatian Peach' foxglove seedlings as a function of the amount of supplemental far-red light $(700-800 \mathrm{~nm})$ provided. Plants also received an average photosynthetic photon flux density $(P P F D)$ of $186.0 \pm 6.4 \mu \mathrm{mol} \cdot \mathrm{m}^{-2} \cdot \mathrm{s}^{-1}$; $1 \mathrm{~g}=0.0353 \mathrm{oz}$. that the cropping cycle of foxglove seedlings can be shortened by at least 1 week $(54 \mathrm{~d} \times 0.2=10.8 \mathrm{~d})$. Shortening the cropping cycle by at least 1 week is needed for a practical impact on production, because greenhouse production and shipping schedules are typically based on weeks, not days.

Root weight fraction decreased linearly from 0.198 to $0.166(16 \%)$ as far-red light increased from 4.0 to $68.8 \mu \mathrm{mol} \cdot \mathrm{m}^{-2} \cdot \mathrm{s}^{-1}$ (Fig. 2C). This finding was not unexpected, and we propose two possible explanations: 1 ) far-red light can increase biomass allocation to above-ground plant tissue, a shade-acclimation response to increase light capture (Valladares et al., 2016), or 2) it may simply be the result of bigger plants having a lower root weight fraction (Elkins, 2020). This increased plant growth with increased far-red light may be due to 1 ) a shade response resulting in a larger canopy and 2) increased photosynthesis.
Morphological response. Stem elongation is a typical shadeavoidance response mediated by phytochrome, which detect changes in the R:FR ratio (Franklin, 2008; Morgan and Smith, 1981; Ruberti et al., 2012). Creating a far-red deficient light environment can reduce stem elongation of ornnamental plants (Runkle and Heins, 2002), while adding far-red light can increase stem elongation ( $\mathrm{Li}$ and Kubota, 2009; Mah et al., 2018; Park and Runkle, 2017; Yang et al., 2012). As far-red light increased from 4.0 to 68.8 $\mu \mathrm{mol} \cdot \mathrm{m}^{-2} \cdot \mathrm{s}^{-1}$ in this study, plant height increased linearly from 8.4 to $11.6 \mathrm{~cm}$, or by $38 \%$ (Fig. 3A), suggesting a shade-avoidance response. However, far-red light not only increased plant height, it also increased shoot and root dry weight. Although plant height is an obvious and common measurement to assess shade responses, it also is a poor indicator of elongation, because it cannot

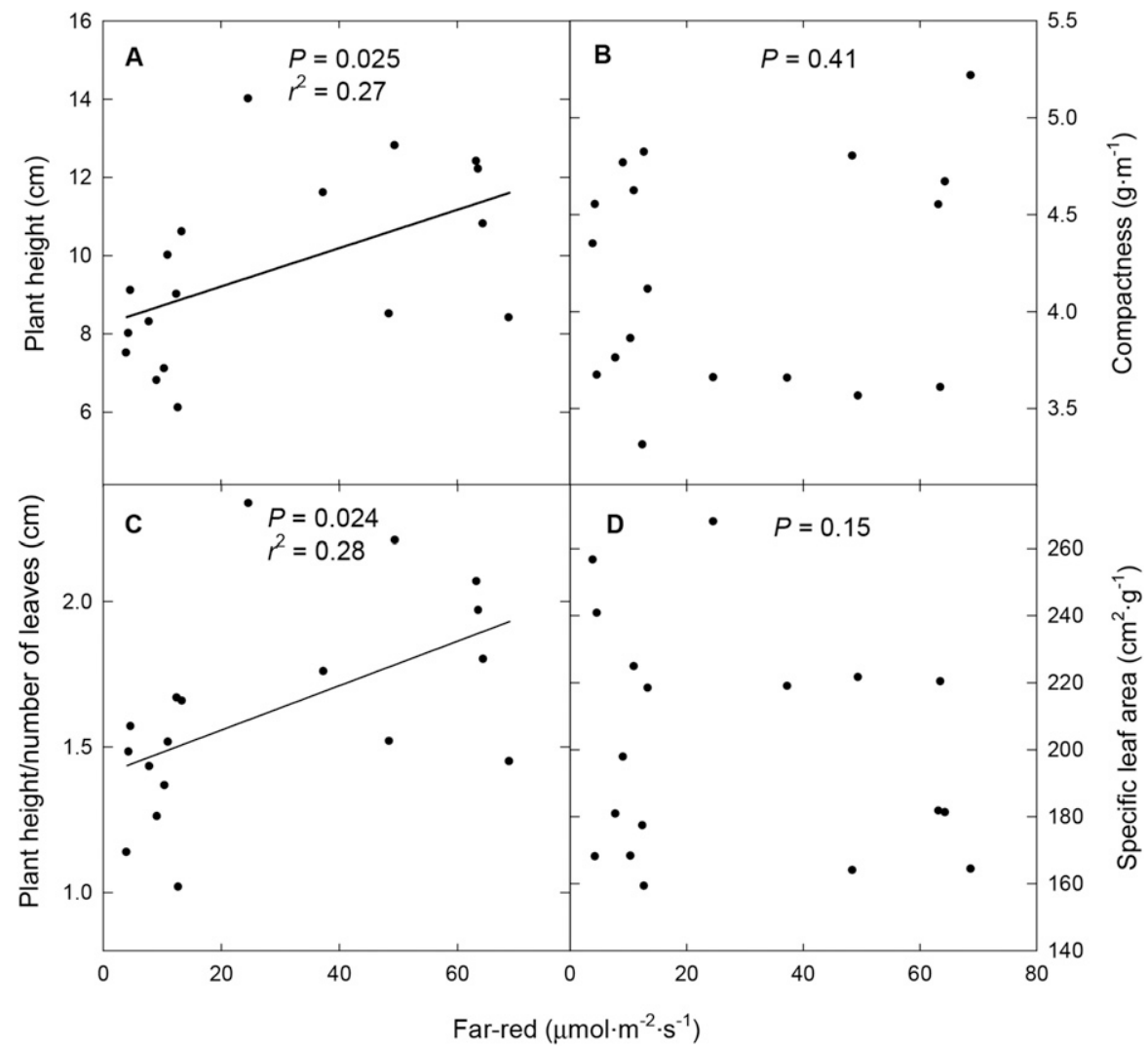

Fig. 3. (A) Plant height $(8.230+0.049 \times$ far-red $)$, (B) compactness, (C) plant height $/$ number of leaves (plant height $/$ number of leaves $=1.405+0.0076 \times$ farred), (D) and specific leaf area of 'Dalmatian Peach' foxglove seedlings as a function of the amount of supplemental far-red light $(700-800 \mathrm{~nm})$ provided. Plants also received an average photosynthetic photon flux density $(P P F D)$ of $186.0 \pm 6.4 \mu \mathrm{mol} \cdot \mathrm{m}^{-2} \cdot \mathrm{s}^{-1}$; $1 \mathrm{~cm}=0.3937$ inch, $1 \mathrm{~g} \cdot \mathrm{m}^{-1}=0.0108 \mathrm{oz} / \mathrm{ft}, 1 \mathrm{~cm}^{2} \cdot \mathrm{g}^{-1}=4.3924 \mathrm{inch}^{2} / \mathrm{oz}$. 
distinguish between plants that grow faster (increased dry weight) vs. plants that elongate rapidly without additional biomass production (stretching). In addition, foxglove seedlings produce a rosette with a very short stem. Our plant height data indicates the height of the tallest leaf, not the apical meristem, and there was no visible effect of far-red light on the actual stem length. More meaningful measures of leaf and stem elongation include SLA, compactness (shoot dry weight/plant height), and plant height/number of leaves.

Plant compactness was unaffected by far-red light (Fig. 3B). Because plant height increased with increasing far-red light and the number of leaves per plant was unaffected, the plant height/number of leaves increased linearly from 1.44 to 1.93 $\mathrm{cm}$, or by $34 \%$, as far-red light increased from 4.0 to $68.8 \mu \mathrm{mol} \cdot \mathrm{m}^{-2} \cdot \mathrm{s}^{-1}$ (Fig. 3C).

Increased leaf expansion is a typical shade-acclimation response, which may also result in thinner leaves and increased SLA (Franklin, 2008). Prior studies have reported increased leaf area with addition of far-red light (Li and Kubota, 2009; Park and Runkle, 2017; Yang et al., 2012). Mah et al. (2018) reported a quadratic response of SLA of 'Antigua Orange' marigold (Tagetes erecta) to supplemental far-red light intensity, while the SLA of 'Duvet Red' petunia, 'Kabloom Deep Blue' calibrachoa (Calibrachoa $\times$ bybrida), and 'Pinto Premium Salmon' geranium was unaffected by far-red light. Our data for foxglove seedlings show no significant effect of far-red light on leaf area (which averaged $73 \mathrm{~cm}^{2} /$ plant $)$, leaf size ( $12.3 \mathrm{~cm}^{2} /$ leaf $)$, or SLA, which averaged $200 \mathrm{~cm}^{2} \cdot \mathrm{g}^{-1}$ (Fig. 3D). Thus, far-red light levels used in this study do not seem to affect leaf elongation of foxglove.

INCREASED PHOTOSYNTHESIS. Far-red light increases the efficiency with which shorter wavelengths of light can be used for photosynthesis (Zhen and van Iersel, 2017). Photons with wavelengths up to at least 732 $\mathrm{nm}$ are photosynthetically active (Zhen et al., 2019). Recently, farred light was shown to be as photosynthetically active as light in the 400 to $700 \mathrm{~nm}$ range, but only if the farred light is combined with light in the $P A R$ range (Zhen and Bugbee, 2020). Far-red light may thus increase growth through increased photosynthesis. Our lighting treatments supplied an average PPFD of $186 \mu \mathrm{mol} \cdot \mathrm{m}^{-2} \cdot \mathrm{s}^{-1}$, and we added up to $69 \mu \mathrm{mol} \cdot \mathrm{m}^{-2} \cdot \mathrm{s}^{-1}$ of farred light, a $37 \%$ increase in total photon flux density. This resulted in a $34 \%$ increase in plant dry weight. The lack of effects from far-red light on compactness, leaf area, and SLA, combined with the known photosynthetic activity of far-red light suggests that the addition of far-red light increased overall growth by increasing photosynthesis, rather than through shade-avoidance/ acclimation responses. It cannot be ruled out that an increase in PPFD would have a similar effect on growth of foxglove seedlings as increased farred light.

\section{Conclusions}

The size of the root system is an important indicator of plug quality because it determines when the plug is ready to transplant. Based on the observed $20 \%$ increase in root dry weight of foxglove seedlings in response to far-red light, we estimate that added far-red light can shorten the cropping cycle by at least 1 week. The increased plant growth in response to added far-red light was likely due to increased photosynthesis, rather than a shade-acclimation response, because we found no significant effect of far-red light on leaf area, SLA, or compactness, which are typical measures of a shade response. Because the observed effects appear to be due to the photosynthetic rather than morphological effects of far-red light, it is possible that increased PPFD, rather than far-red light, would result in similar increases in growth.

\section{Literature cited}

Casal, J.J. 2013. Canopy light signals and crop yield in sickness and in health. ISRN Agron. 2013, doi: 10.1155/2013/650439.

Elkins, C.A. 2020. Evaluation of different lighting strategies used to improve efficiencies in plant growth for controlled environment agriculture. MS Thesis, Univ. Georgia, Athens.

Evans, J.R. and H. Poorter. 2001. Photosynthetic acclimation of plants to growth irradiance: The relative importance of specific leaf area and nitrogen partitioning in maximizing carbon gain. Plant Cell Environ. 24:755-767.
Franklin, K.A. 2008. Shade avoidance. New Phytol. 179:930-944.

Franklin, K.A. and G.C. Whitelam. 2005. Phytochromes and shade-avoidance responses in plants. Ann. Bot. 96:169-175.

Gommers, C.M., E.J. Visser, K.R. St Onge, L.A. Voesenek, and R. Pierik. 2013. Shade tolerance: When growing tall is not an option. Trends Plant Sci. 18:65-71.

Gong, W.Z., C.D. Jiang, Y.S. Wu, H.H. Chen, W.Y. Liu, and W.Y. Yang. 2015. Tolerance vs. avoidance: Two strategies of soybean (Glycine max) seedlings in response to shade in intercropping. Photosynthetica 53:259-268.

Hoover, W.H. 1937. The dependence of carbon dioxide assimilation in a higher plant on wave length of radiation. Smithson. Misc. Collect. 95(21):1-13.

Hurt, A., R.G. Lopez, and J.K. Craver. 2019. Supplemental but not photoperiodic lighting increased seedling quality and reduced production time of annual bedding plants. HortScience 54:289-296.

Inada, K. 1976. Action spectra for photosynthesis in higher plants. Plant Cell Physiol. 17:355-365.

Keuskamp, D.H., R. Sasidharan, and R. Pierik. 2010. Physiological regulation and functional significance of shade avoidance responses to neighbors. Plant Signal. Behav. 5:655-662.

Li, Q. and C. Kubota. 2009. Effects of supplemental light quality on growth and phytochemicals of baby leaf lettuce. Environ. Expt. Bot. 67:59-64.

Mah, J.J., D. Llewellyn, and Y. Zheng. 2018. Morphology and flowering responses of four bedding plant species to a range of red to far red ratios. HortScience 53:472-478.

McCree, K.J. 1971. The action spectrum, absorptance and quantum yield of photosynthesis in crop plants. Agr. Meteorol. 9:191-216

Meng, Q.W., N. Kelly, and E.S. Runkle. 2019. Substituting green or far-red radiation for blue radiation induces shade avoidance and promotes growth in lettuce and kale. Environ. Expt. Bot. 162:383391.

Meng, Q.W. and E.S. Runkle. 2019. Farred radiation interacts with relative and absolute blue and red photon flux densities to regulate growth, morphology, and pigmentation of lettuce and basil seedlings. Scientia Hort. 255:269-280.

Morgan, D. and H. Smith. 1981. Control of development of Chenopodium album $\mathrm{L}$. by shadelight: The effect of light quality (total fluence rate) and light quality 
(red:far-red ratio). New Phytol. 88:239248

Park, Y. and E.S. Runkle. 2016. Investigating the merit of including far-red radiation in the production of ornamental seedlings grown under sole-source lighting. Acta Hort. 1134:259-266.

Park, Y. and E.S. Runkle. 2017. Far-red radiation promotes growth of seedlings by increasing leaf expansion and whole-plant net assimilation. Environ. Expt. Bot. 136:41-49.

Possart, A., C. Fleck, and A. Hiltbrunner. 2014. Shedding (far-red) light on phytochrome mechanisms and responses in land plants. Plant Sci. 217:36-46.

Purdue University. 1997. Foxglove. 9 July 2020. <https://hort.purdue.edu/ newcrop / med-aro/factsheets / FOXGLOVE.html>.

Randall, W.C. and R.G. Lopez. 2015. Comparison of bedding plant seedlings grown under sole-source light-emitting diodes (LEDs) and greenhouse supplemental lighting from LEDs and highpressure sodium lamps. HortScience 50:705-713.

Ruberti, I., G. Sessa, A. Ciolfi, M. Possenti, M. Carabelli, and G. Morelli. 2012. Plant adaptation to dynamically changing environment: The shade avoidance response. Biotechnol. Adv. 30:1047-1058.
Runkle, E.S. and R.D. Heins. 2002. Stem extension and subsequent flowering of seedlings grown under a film creating a far-red deficient environment. Scientia Hort. 96:257-265.

Sager, J., W. Smith, J. Edwards, and K. Cyr. 1988. Photosynthetic efficiency and phytochrome photoequilibria determination using spectral data. Trans. Amer. Soc. Agr. Eng. 31:1882-1889.

Stutte, G.W., S. Edney, and T. Skerritt. 2009. Photoregulation of bioprotectant content of red leaf lettuce with lightemitting diodes. HortScience 44:79-82.

Valladares, F., L. Laanisto, U. Niinemets, and M.A. Zavala. 2016. Shedding light on shade: Ecological perspectives of understorey plant life. Plant Ecol. Divers. 9:237-251.

Yang, Z.-C., C. Kubota, P.-L. Chia, and M. Kacira. 2012. Effect of end-of-day farred light from a movable LED fixture on squash rootstock hypocotyl elongation. Scientia Hort. 136:81-86.
Zhen, S. and B. Bugbee. 2020. Far-red photons have equivalent efficiency to traditional photosynthetic photons: Implications for re-defining photosynthetically active radiation. Plant Cell Environ. 2020:1-14.

Zhen, S., M. Haidekker, and M.W. van Iersel. 2019. Far-red light enhances photochemical efficiency in a wavelength-dependent manner. Physiol. Plant. 167:2133 .

Zhen, S. and M.W. van Iersel. 2017. Farred light is needed for efficient photochemistry and photosynthesis. J. Plant Physiol. 209:115-122.

Zou, J., Y. Zhang, Y. Zhang, Z. Bian, D. Fanourakis, Q. Yang, and T. Li. 2019. Morphological and physiological properties of indoor cultivated lettuce in response to additional far-red light. Scientia Hort. 257:108725. 